Check for updates

The BMJ

Cite this as: BMJ 2021;372:n179 http://dx.doi.org/10.1136/bmj.n179 Published: 20 January 2021

Q\&A

\title{
Covid 19: How to feel safe working on the front line-your legal and ethical questions answered
}

The pandemic has presented doctors with legal and ethical challenges around how to treat patients in overstretched health services. Clare Dyer examines some of the key questions

Clare Dyer

\section{If resources such as critical care are insufficient, who decides which patients need to be prioritised, and how will the decision be taken?}

Many NHS trusts will have guidelines or protocols to help doctors decide. Guidance is also available from the BMA's ethics committee, ${ }^{1}$ the National Institute for Health and Care Excellence, ${ }^{2}$ and the Royal College of Physicians. ${ }^{3}$ The basic principle is to use the resources available to try to ensure the greatest medical benefit for the greatest number of patients.

Admission to intensive care or access to advanced life support may depend on whether the patient has responded to treatment within a certain time frame. Decisions should not be based purely on the patient's age or any disability or medical condition. But where age, disability, or medical condition means that the patient is significantly less likely to survive the treatment, this becomes a relevant factor, says the BMA guidance.

\section{Could my trust face a clinical negligence claim if I denied a patient a critical care bed, or took a patient off a ventilator, to give it to another who was judged to have a better chance of survival?}

Doctors will not be found negligent if their actions meet the standard of a responsible body of medical opinion. In one court case the judge accepted that doctors in emergency departments must make quick judgments without the luxury of consulting others. He confirmed that "the standard of care owed by an [accident and emergency] doctor must be calibrated in a manner reflecting reality." 4

In a legal opinion this month, the healthcare law specialist David Lock QC argued that it would be "exceptionally difficult to establish that doctors have acted negligently during this pandemic.” Lock, a member of the BMA ethics committee who sits part time as a High Court judge, added, "Only when blatant and egregious errors have occurred should doctors be concerned, and in such cases any immunity would be wholly inappropriate. Most doctors, therefore, have nothing to fear from the law of negligence." 5

\section{Can I be required to work in a different specialty during the pandemic?}

NHS employers have been advised that implied terms in an employee's contract, including the obligation to follow reasonable management instructions, can be relied on in a national crisis "to encourage people to move into other roles where these moves are necessary to reduce/remove the spread of and treat covid-19." The law firm Capsticks, which acts for a number of NHS organisations, advises that the availability of other staffing resources should be considered in deciding whether an instruction was reasonable, along with the individual's current role, skills, and expertise. ${ }^{6}$

The BMA advises that doctors and students should work only within their area of competence and should receive adequate training and supervision. If pressured to work outside their competence they are advised to contact the BMA for support. They should also tell their medical defence organisation if they are working in a different field.

Could doctors be at risk of investigation for gross negligence manslaughter as a result of a decision to deny treatment, such as taking a patient off a ventilator?

This fear was a major factor in prompting doctors' organisations to write to England's health and social care secretary, Matt Hancock, asking for new emergency laws to protect them from "inappropriate" legal action. ${ }^{7}$ Hancock has said he doesn't believe that this is necessary "at this point." 8

Lock sees "no reasonable prospect" that a doctor would be prosecuted for medical manslaughter for following an NHS organisation's clear prioritisation policy. William Childs and Stewart Duffy, partners in the law firm RadcliffesLeBrasseur, write that manslaughter charges could, in principle, be brought for alleged failure to provide or continue treatment. But they hope that police will be mindful that, "in the heat of the most extraordinary public health emergency in living memory," doctors will often find themselves "in an almost impossible position."

\section{Could I face misconduct charges from the General Medical Council over my treatment decisions?}

The GMC's guidance says that, in launching any investigation, it will take account of the difficult 
decisions doctors have to make in the current extremely challenging circumstances. It will also consider any guidelines or protocols in place, the resources available, the problems of working in unfamiliar areas of practice, stress, and tiredness. ${ }^{10}$ Lock writes, "I cannot see any legal basis for a doctor being held to be unfit by applying the terms of a lawful NHS rationing policy [on covid-19 treatment] and thus being struck off the medical register, any more than a doctor could be unfit for following any other NHS rationing policy."

\section{I'm feeling anxious and overwhelmed. Where can I get support?}

A list of organisations providing support for doctors is available on NHS Resolution's “Support for practitioners” page. ${ }^{11}$ The emotional support charity Samaritans is operating a confidential staff support line for NHS staff in England and Wales. This can be accessed by phone (0800 0696 222, from 7 am to 11 pm, seven days a week) or by texting FRONTLINE to 85258 at any time.

$1 \quad$ BMA. COVID-19-ethical issues and decision making when demand for life-saving treatment is at capacity. Updated Jan 2021. https://www.bma.org.uk/media/3657/bma-covid-19-ethics-guidance-jan-2021.pdf.

2 National Institute for Health and Care Excellence. Coronavirus (COVID-19). https://www.nice.org.uk/covid-19.

3 Royal College of Physicians. Ethical guidance published for frontline staff dealing with pandemic Updated Dec 2020. https://www.rcplondon.ac.uk/news/ethical-guidance-published-frontlinestaff-dealing-pandemic.

4 Mulholland v Medway NHS Foundation Trust [2015] EWHC 268 at [101] per Greene . https://www.bailii.org/ew/cases/EWHC/QB/2015/268.html.

5 Lock D. Legal issues arising out of medical priority decision making. 8 Jan 2021. https://www.linkedin.com/pulse/legal-issues-arising-out-medical-priority-decision-making-lockqc/?trk=public_post_promoted-post.

6 Green N, Parkinson S. COVID-19: workforce FAQs. Capsticks. 12 Jan 2021. https://www.capsticks.com/insights/covid-19-workforce-faqs.

7 Medical Protection Society. UK healthcare leaders unite in call to protect doctors as pressure on health service grows. Jan 2021. https://www.medicalprotection.org/uk/articles/uk-healthcareleaders-unite-in-call-to-protect-doctors-as-pressure-on-health-service-grows.

8 Dyer C. Covid-19: Doctors' call for legal protection against claims of unlawful killing is rejected. BMJ 2021;372;n164.

9 Childs W, Duffy S. Gross negligence manslaughter- tolerating risk in the era of coronavirus. RadcliffesLeBrasseur. 20 Apr 2020. https://www.rlb-law.com/briefings/healthcare/gross-negligence-manslaughter-tolerating-risk-in-the-era-of-coronavirus/.

10 General Medical Council. COVID-19: assessing the risk to public protection posed by a doctor as a result of concerns about their practice during the pandemic. 14 Sep 2020. https://www.gmcuk.org/-/media/documents/dc13028-guidance-for-decision-makers-on-covid-19--external-version_pdf-83985701.pdf.

11 NHS Resolution. Support for practitioners. https://resolution.nhs.uk/services/practitioner-performance-advice/advice/support-for-practitioners/.

This article is made freely available for use in accordance with BMJ's website terms and conditions for the duration of the covid-19 pandemic or until otherwise determined by BMJ. You may use, download and print the article for any lawful, non-commercial purpose (including text and data mining) provided that all copyright notices and trade marks are retained. 